\title{
ASUHAN KEBIDANAN PADA IBU HAMIL DENGAN KONSTIPASI DI PMB HASNA DEWI PEKANBARU TAHUN 2020
}

\author{
Kiki Megasari \\ STIKes Hang Tuah Pekanbaru
}

\begin{abstract}
Constipation is a barrier to expelling food debris related to difficulty defecating, characterized by defecating less than 3 times a week due to hard stools accompanied by abdominal pain. About 11\% to $38 \%$ of pregnant women experience constipation, which is caused by a decrease in intestinal peristalsis due to an increase in the hormone progesterone. In addition, lack of fiber intake and fluid intake can also cause constipation. The purpose of this case study is to provide comprehensive and sustainable obstetric care for pregnant women with constipation using the SOAP method. The method used is descriptive observational method with the Continuity of care approach given to pregnant women, Mrs. S at BPM Hasna Dewi, Amd.Keb, SKM from 01-06 September 2020. The subject is Mrs. S, 26 years old G1P0A0. Primary data types. How to collect anamnesa data, observation, examination and documentation. Data analysis by comparing the data obtained with existing theories. The result of the care given was that after 6 days of care, it was obtained from 2 visits of pregnant women who experienced constipation by consuming papaya fruit and fluid intake which resulted in the discomfort of pregnant women with resolved constipation. From the management given, namely overcoming constipation by consuming foods high in fiber such as papayas, bananas, apples, spinach, cauliflower and carrots and drinking at least 8-10 glasses of water per day. After that, doing an evaluation and the results obtained are Mrs. S was successful in overcoming constipation and has had one bowel movement every day. For advice, it is hoped that midwifery service providers will always provide health education to pregnant women, especially in the third trimester who experience constipation.
\end{abstract}

Keywords: Midwifery Care, Constipation, Pregnant Women

\begin{abstract}
ABSTRAK
Konstipasi adalah hambatan pengeluaran dari sisa-sisa makanan yang berkaitan dengan kesulitan buang air besar, ditandai dengan buang air besar kurang dari 3x seminggu akibat tinja yang keras disertai dengan nyeri pada perut. Sekitar 11\% sampai 38\% ibu hamil mengalami konstipasi, yang diakibatkan karena penurunan dari peristaltik usus akibat dari peningkatan hormon progesterone. Selain itu kurangnya asupan serat, dan asupan cairan juga dapat menyebabkan konstipasi. Tujuan studi kasusu ini untuk melakukan asuhan kebidanan pada ibu hamil dengan konstipasi secara menyeluruh dan berkesinambungan dengan menggunakan metode SOAP. Metode yang dilakukan menggunakan metode deskriptif observasional dengan pendekatan Continuity of care diberikan pada ibu hamil Ny. S di BPM Hasna Dewi, Amd.Keb, SKM dari 01-06 September 2020. Subyeknya Ny. S umur 26 tahun G1P0A0. Jenis data primer. Cara pengumpulan data anamnesa, observasi, pemeriksaan dan dokumentasi. Analisa data dengan membandingkan antara data yang diperoleh dengan teori yang ada. Hasil dari asuhan yang dilakukan adalah setelah dilakukan asuhan selama 6 hari didapatkan dari 2 kali kunjungan ibu hamil yang mengalami konstipasi dengan mengkonsumsi buah pepaya dan asupan cairan menghasilkan ketidaknyamanan ibu hamil dengan konstipasi teratasi. Dari penatalaksanaan yang diberikan yaitu mengatasi konstipasi dengan cara mengkonsumsi makan-makanan yang tinggi serat seperti buah pepaya, pisang, apel, sayur bayam, kembang kol, dan wortel serta minum air putih minimal 8-10 gelas perhari. Setelah itu, melakukan evaluasi dan hasil yang didapat adalah $\mathrm{Ny}$. S berhasil mengatasi konstipasi dan telah BAB satu hari sekali. Untuk saran diharapkan kepada penyedia layanan kebidanan untuk selalu memberikan pendidikan kesehatan pada ibu hamil terutama trimester III yang mengalami konstipasi.
\end{abstract}

Kata Kunci : Asuhan Kebidanan, Konstipasi, Ibu Hamil 


\section{PENDAHULUAN}

Konstipasi adalah kelainan pada sistem pencernaan yang ditandai dengan adanya tinja yang keras sehingga buang air besar menjadi jarang, sulit dan nyeri. Hal ini disebabkan karena ada tinja yang padat dan keras saat keluar dari anus yang dapat menyebabkan perubahan akibat fisura ani (Akmal dkk, 2010).

Konstipasi terjadi apabila frekuensi BAB kurang dari 3 kali dalam seminggu disertai konsistensi feses yang keras, kesulitan mengeluarkan feses (akibat ukuran feses besar-besar maupun akibat terjadinya gangguan refleks defekasi), serta mengalami perasaan tidak puas pada saat buang air besar. Frekuensi defekasi yang kurang dari normal belum tentu dapat dikatakan menderita konstipasi apabila ukuran ataupun konsistensi feses tersebut masih normal (Herawati, 2012).

Di Indonesia lebih dari 2,5 juta penduduk mempunyai keluhan sering konstipasi, hingga prevelensinya mencapai sekitar $2 \%$ penderita berkunjung ke dokter setiap tahunnya. Konstipasi diperkirakan menyebabkan 2,5 juta penderita berkunjung ke dokter setiap tahunnya. Kasus konstipasi yang diderita wanita hamil sekitar 4-30\%, ternyata wanita hamil mengeluh kesulitan buang air besar (Sulistiyowati, 2016).

Angka kejadian konstipasi pada ibu hamil berkisar antara 11-38\%, yang diakibatkan karena penurunan dari peristaltic usus akibat dari peningkatan hormone progesterone. Studi dilakukan oleh Bradley tahun 2007 mendapat sil bahwa konstipasi terjadi pada trimester I sebanyak $24 \%, 26 \%$ pada mester II dan $24 \%$ pada trimester III, serta kejadiannya meningkat 4 kali pada ibu dengan riwayat konstipasi (Irianti dkk, 2014)

Susah buang air besar sering dialami oleh ibu hamil. Perubahan hormone akibat kehamilan atau pola hidup dapat memicu timbulnya gangguan ini. Awalnya sembelit hanya menyebabkan ketidaknyamanan selama buang air besar dan perut menjadi sakit atau kembung, tetapi jika ini berlangsung lama akan mengganggu metabolisme tubuh dan menimbulkan gangguan tubuh lainnya. Pembesaran uterus menimbulkan sejumlah ketidaknyamanan normal pada kehamilan salah satunya konstipasi. Adapun dampak konstipasi yaitu dapat meningkatkan rasa tidak nyaman pada ibu hamil akibat gangguan dalam proses eliminasi. Selain itu, konstipasi dapat memicu terjadinya haemoroid yang berisiko pecahnya pembuluh darah vena pada daerah anus (Kartikasari \& Payana, 2017)

Konstipasi pada wanita hamil umumnya merupakan konstipasi fungsional. Ada beberapa faktor mengapa 
wanita hamil mengalami konstipasi yakni: faktor hormonal, perubahan diet, pertumbuhan janin dan aktifitas fisik. Riwayat posisi saat defekasi juga menjadi risiko untuk timbulnya konstipasi. Selain itu, konstipasi terjadi akibat aktivitas ibu yang kurang, asupan cairan dan serat yang rendah juga dapat menjadi faktor terjadinya konstipasi (Irianti, 2014).

Menurut Bradley C.S (2007), Wanita yang mengkonsumsi suplemen zat besi mengalami 3,5 kali lebih banyak konstipasi dibandingkan yang tidak konsumsi zat besi, sedangkan wanita yang mendapat penanganan konstipasi dimasa lalu mengalami 3 kali lipat risiko konstipasi selama kehamilan karena dalam zat besi mengandung Cupri Sulfat dan Mangan Sulfat merupakan biokatalisator yang merangsang jaringan pembentukan darah dalam tubuh yang menyebabkan peningkatan hormon progesterone yang memperlambat proses pencernaan yang membuat kondisi fases cenderung lebih keras dan lebih sulit keluar (Yunita, 2015). Pemeriksaan kehamilan yang diberikan kepada setiap ibu hamil perlu diupayakan agar berkualitas dan memenuhi standar pelayanan kebidanan agar aman dan efektif (Nisak, 2018)

Kesehatan pencernaan saat hamil memiliki peran besar terhadap perkembangan janin dan kesehatan tubuh ibu hamil. Karena pada saat kehamilan, bayi mendapatkan nutrisi untuk berkembang melalui asupan ibu. Jadi, diperlukan kesehatan pencernaan yang optimal dari ibu untuk memastikan kesehatan ibu hamil dan bayi berada dalam kondisi prima (Trottier, et al., 2012).

Ibu hamil yang mengalami ketidaknyamanan dengan perutnya, akan mudah kehilangan nafsu makan. Hal ini menyebabkan, asupan nutrisi untuk ibu hamil dan janin akan berkurang. Oleh karena itu, penting bagi ibu hamil untuk menjaga kesehatan pencernaan, termasuk mengatasi konstipasi, agar asupan nutrisi yang ibu dan janin butuhkan bisa terpenuhi (Aritonang, E., 2010).

Peran bidan dalam memberikan asuhan kebidanan untuk mengatasi konstipasi pada ibu hamil yaitu dengan memberikan asuhan kebidanan berupa konseling tentang pengertian konstipasi serta menjelaskan pola makan sehari-hari dengan makanan kaya serat seperti, buahbuahan dan sayuran serta minum air yang banyak (Yunita, 2013).

\section{METODE}

Studi kasus ini menggunakan metode deskriptif observasional dengan pendekatan Contuinity of care di berikan pada ibu hamil Ny. S di BPM Hasna Dewi, Amd.Keb, SKM Jl.HR. Soebrantas 
Panam, Sidomulyo Bar., Kec. Tampan, Kota Pekanbaru dari 01-06 September 2020. Subyeknya Ny. S umur 26 tahun G1P0A0. Jenis data primer. Cara pengumpulan data anamnesa, observasi, pemeriksaan dan dokumentasi. Analisa data dengan membandingkan antara data yang diperoleh dengan teori yang ada.

\section{HASIL}

Kunjungan antenatal care pertama kali dilakukan pada tanggal 01 September 2020

\section{Data Subjektif}

- Keluhan yang dirasakan : sudah 3 hari tidak buang air besar, perutnya terasa penuh atau begah dan terasa sakit saat $\mathrm{BAB}$.

- Jarang minum air putih paling banyak 6 gelas perhari, jarang mengkonsumsi buah dan sayur

- Riwayat kesehatan yang lalu : tidak mempunyai riwayat penyakit degeneratif seperti penyakit Jantung, Diabetes, Asma dan lainlain.

\section{Data Objektif}

- Keadaan umum : baik, kesadaran composmentis. Tekanan Darah 111/72 mmHg, Pernafasan $20 \mathrm{x} / \mathrm{i}$, Nadi 80 x/i, Suhu $36,1^{\circ} \mathrm{c}$, sklera tidak ikterik, konjungtiva merah muda. BB sebelum hamil $57 \mathrm{~kg}$, BB sekarang 67,5 kg, Tinggi Badan
$151 \mathrm{~cm}$, HPHT 16-12-2019, UK 36 minggu 4 hari, TP 23-09-2020.

- Pemeriksaan Palpasi :

Leopold I :

TFU 1 jari bawah Px, bagian atas perut ibu teraba bundar, lembek, tidak melenting, kemungkinan bokong janin.

Leopold II :

Bagian kanan perut ibu teraba panjang, keras, memapan kemugkinan punggung janin. Bagian kiri perut ibu teraba bagiam kecil janin kemungkinan ekstemitas janin.

Leopold III :

Bagian bawah perut ibu teraba bulat, keras melenting kemungkinan kepala janin, sudah masuk PAP.

Leopold IV :

Divergen

- MC. Donald : $33 \mathrm{~cm}$

- TBBJ : (33-11) x $151=$ 3322 gram

- DJJ : 146 x/i

- Pemeriksaan Laboratorium : tidak dilakukan

3. Analisis

G1P0A0 uk 36 minggu 4 hari dengan konstipasi 3 hari. 
Janin hidup, tunggal, intrauterine, puka, preskep, DJJ dalam batas normal.

4. Penatalaksanaan

1) Menginformasikan hasil pemeriksaan kepada ibu dan keluarga bahwa keadaan umum ibu dan janin baik.

2) Memberikan KIE kepada ibu mengenai penyebab konstipasi:

- Perubahan hormonal yang drastis yakni peningkatan progesteron selama kehamilan yang menurunkan motilitas usus dan pada akhirnya menyebabkan konstipasi.

- Berkurangnya asupan makanan khususnya minuman yang menyebabkan tinja keras sehingga sulit untuk dikeluarkan.

- Pemberian suplemen besi dan kalsium selama kehamilan yang membuat kondisi fases cenderung lebih keras dan lebih sulit keluar.

- Uterus yang semakin membesar yang memberikan tekanan pada usus sehingga semakin mudah terjadinya konstipasi

- Ibu hamil biasanya cenderung malas dan kurang bergerak, hingga aliran darahnya pun tidak lancar.

- Ibu hamil cenderung lebih nyaman defekasi dengan posisi duduk tetapi dapat berakibat timbulnya konstipasi karena membutuhkan tenaga mengedan yang lebih kuat.

- Kurang minum air dan makanan kurang serat akan menyebabkan tinja keras sehingga sulit untuk dikeluarkan.

3) Memberikan KIE kepada ibu jika konstipasi tidak segera diatasi akan menimbulkan haemoroid (pelebaran vena dari anus)

4) Memberikan KIE kepada ibu mengenai pencegahan konstipasi:

- Menganjurkan ibu untuk makan-makanan yang banyak mengandung serat pada sayuran dan buahbuahan seperti, wortel, kacang panjang, kembang kol, bayam, pepaya, pisang, atau apel.

- Memberitahukan ibu untuk 
minum 8-10 gelas dalam

sehari, serta menghindari

minuman yang dapat

memperberat kerja sistem

pencernaan seperti kopi dan

teh.

- Memberitahukan ibu minum

air putih hangat ketika perut

dalam keadaan kosong

dapat merangsang geras

paristaltic usus.

- Menganjurkan ibu untuk

olahraga ringan atau

mengikuti senam hamil atau

sekedar berjalan-jalan

ringan setiap harinya.

5) Persiapan persalinan

- Memperkenalkan tanda-

tanda persalinan seperti

mules, keluar tanda lendir

dan darah.

- Mempersiapkan pakaian ibu dan bayi serta keperluan lainnya di suatu tempat yang mudah dijangkau.

6) Tanda bahaya hamil lanjut Yaitu perdarahan, sakit kepala hebat, demam, air ketuban keluar, gerakan janin berkurang.

7) Memberitahukan kepada ibu untuk melakukan kunjungan ulang tanggal 08-09-2020, dan jika ada keluhan ibu bisa datang sebelum tanggal kunjungan ulang.

\section{PEMBAHASAN}

Berdasarkan hasil asuhan yang dilakukan di BPM Hasna Dewi Kota Pekanbaru yang dilakukan pada tanggal 01 September 2020 sampai tanggal 06 September 2020 yaitu dimulai dari usia kehamilan 36 minggu 4 hari - 37 minggu 2 hari, tentang Asuhan Kebidanan pada Ibu Hamil dengan Konstipasi pada Ny. R ditemukan pada kehamilan ini ibu mengalami sulit untuk buang air besar, ibu sudah 3 hari tidak ada buang air besar. Masalah ini merupakan salah satu ketidaknyamanan yang terjadi pada ibu hamil. Menurut (Proverawati \& Wati, 2017) konstipasi adalah hambatan pengeluaran dari sisasisa makanan yang berkaitan dengan kesulitan buang air besar akibat tinja yang keras disertai dengan nyeri pada perut.

Mengacu pada keluhan sulit buang air besar yang dirasakan ibu, penulis menjelaskan penyebab sulitnya buang air besar yang ibu rasakan. Menurut (Syafrudin et al., 2011) konstipasi disebabkan perubahan hormonal tubuh, yakni meningkatnya hormone progesterone, penekanan usus akibat rahim yang membesar membuat sisa-sisa pencernaan relatif tertumpuk diusus. Selain itu, menurut (Irianti et al., 
2014) konstipasi terjadi akibat aktifitas ibu yang kurang, penyerapan air dan suplemen zat besi. Asupan cairan dan serat yang rendah juga dapat menjadi faktor terhadap terjadinya konstipasi.

Jika tidak segera diatasi konstipasi akan menimbulkan dampak yaitu meningkatnya rasa tidak nyaman pada ibu hamil akibat gangguan dalam proses eliminasi. Selain itu, menurut (Syafrudin et al., 2011) dampak konstipasi dapat menimbulkan haemoroid yaitu pelebaran vena dari anus.

Pada asuhan ini penulis menganjurkan ibu untuk makan-makanan yang banyak mengandung serat pada sayuran dan buah-buahan seperti, wortel, kacang panjang, kembang kol, bayam, pepaya, pisang, atau apel. Selain itu, ibu harus minum 8-10 gelas dalam sehari, serta menghindari minuman yang dapat memperberat kerja sistem pencernaan seperti kopi atau teh, dan melakukan olahraga ringan atau mengikuti senam hamil atau sekedar berjalan-jalan ringan setiap harinya. Hal ini sesuai dengan teori yang dikemukakan oleh Irianti (2014) yang mengutarakan ibu hamil sebaiknya mengkonsumsi makanan mengandung serat, minum air putih paling sedikit 8-10 gelas dalam sehari serta menghindari minuman yang dapat memperberat kerja sistem pencernaan seperti teh atau kopi, melakukan olahraga ringan secara rutin atau sekedar berjalan-jalan ringan setiap harinya.

Hal ini sesuai dengan hasil penelitian (Tumanggor, 2014) bahwa adanya hubungan yang signifikan antara asupan cairan dengan terjadinya konstipasi pada ibu hamil, adanya hubungan yang signifikan antara asupan makanan dengan terjadinya konstipasi pada ibu hamil dan adanya hubungan yang signifikan antara olahraga dengan terjadinya konstipasi pada ibu hamil. Menurut asumsi peneliti rata-rata penderita konstipasi akan teratasi jika menjaga asupan nutrisinya seperti sayuran hijau, buah yang banyak mengandung serat dan minum air putih sebanyak 8-10 gelas perhari.

\section{KESIMPULAN}

Setelah dilakukan pengkajian sampai evaluasi kasus tidak terdapat kesenjangan antara teori dan praktik di lapangan.

\section{SARAN}

1. Bagi Institusi / Pendidikan

Diharapkan studi kasus yang telah dilakukan dapat menambah sumber wawasan pengetahuan mahasiswi khususnya DIII Kebidanan STIKes Hang Tuah Pekanbaru.

2. Bagi Lahan Praktik

Diharapkan kepada penyedia layanan kebidanan untuk selalu 
memberikan pendidikan kesehatan pada ibu hamil terutama trimester III yang mengalami konstipasi

\section{DAFTAR PUSTAKA}

Karyati, S. (2019). Hubungan Pola Aktivitas Fisik Dengan Konstipasi Pada Ibu Hamil Trimester III Di Puskesmas Gribig Kecamatan. 10(2), 350-357.

Ibu, P., Di, H., Payung, P., \& Pekanbaru, S. (2020). Pengaruh Konsumsi Tablet Fe Dengan Kejadian Konstipasi. 3, 15-19.

Kebidanan, A., Bonjol, I., Panjang, P., Serikat, A. A., Penelitian, J., Kunci, K., \& Tablet, K. (2014). Hubungan Konsumsi Tablet Fe Dengan Kejadian Konstipasi Pada Ibu Hamil Di Jorong Sikabu , Solok Dan Gantiang Di Wilayah Kerja Puskesmas Singgalang Kabupaten Tanah Datar Tahun 2014 Relationship With Consumption Fe
Tablet Event Constipation Pregnant Women In. 8(2), 146-151.

Kemenkes RI. (2012). Standar Asuhan kebidanan. In Keputusan Menteri Kesehatan RI No.938/Menkes/SK/VIII/2012 tentang Standar Asuhan kebidanan.

Insani, A. A., Nurdiyan, A., Yulizawati, Y., Bustami, L. E., Iryani, D., \& Fitrayeni, F. (2017). "Berpikir Kritis” Dasar Bidan Dalam Manajemen Asuhan Kebidanan. Journal of Midwifery, 1(2), 21. https://doi.org/10.25077/jom.1.2.21 $-30.2016$

Wardatin. (2017). Laporan Tugas Akhir. Universitas Muhamhmadiyah Gersik,01, 1-7.

Kartikasari, R. indah, \& Payana, S. H. dwi. (2017). Pregnancy Exercises Dengan KejadianKonstipasi Pada 